\title{
Is a Derived Caton-Deschamps Index for Arthroplasty a Reliable and Valid Measure of Patella Height?
}

\author{
Christian Konrads* \\ Department for Trauma and Reconstructive Surgery, BG Klinik, University of Tübingen, Germany
}

Submission: October 09, 2020; Published: October 20, 2020

*Corresponding author: Christian Konrads, Institutional address: Department for Trauma and Reconstructive Surgery, BG Klinik, University of Tübingen, Schnarrenbergstr. 95, 72076 Tübingen, Germany

\begin{abstract}
Measuring patella height has been a hot topic since decades. Multiple radiological indices exist for native knees and arthroplasty. A concise concept of patella height analysis is needed for daily practice and scientific research.
\end{abstract}

Keywords: TKA; Patella infera; Patella baja; Anterior knee pain; Insall-Salvati

Abbreviations: CDI: Caton-Deschamps-Index; dCDI: derived Caton-Deschamps Index; ISI: Insall-Salvati Index; TKA: Total knee arthroplasty

\section{Perspective}

Determining patella height is daily practice in orthopaedics. True patella height is determined by the length of the patellar ligament. Pseudo patella height alteration is a relative alteration of the patella height referred to the femoro-tibial joint line without change in the length of the patellar ligament [1]. Proximalisation of the joint line can be accidentally created during total knee arthroplasty (TKA) leading to pseudo patella infera (PPI) [24]. Patella infera can be a combination of TPI and PPI. Both components (TPI and PPI) should be part of a complete patella height assessment, which demands a combination of patella height indices. If only one index is to be used, it should be made sure that this index can record functional patella height completely.

The Insall-Salvati index (ISI) [5] records true patella height only [6]. The original Caton-Deschamps index (CDI) [7] published in 1982 is commonly accepted as a measure of functional patella height [8]. As the tibial landmark used for this index is being resected during knee arthroplasty and as the tibial inlay is not visible on X-ray due to its radiolucency, the index in its original form cannot be used in knees with an implanted endoprosthesis. A modified Caton-Deschamps index for knee arthroplasty was published in 2016 [9]. This index follows different principles than the original CDI and measures only true patella height. Therefore, it is only an alternative to the ISI and cannot in all cases record PPI, which is common after TKA.

A derivate of the original CDI could be a simple analogue to the index published in 1982 using a modified tibial reference point at the anterior proximal point of the inlay, which can indirectly be found on the lateral knee radiograph (Figure 1). This modification can be found in the literature, but to my best knowledge it has not been fully evaluated regarding its reliability and validity [10].

The index follows the same principles as the original CDI. I call it "derived Caton-Deschamps Index" (dCDI) and I hypothesize that it has similar reliability and the same reference range as the original CDI. Future studies are needed to evaluate the dCDI. In my opinion, the dCDI could be part of an easy to use concept of patella height analysis consisting of CDI preoperatively and dCDI after implantation of a knee endoprosthesis. Additionally, the ISI could be used to determine the proportion of TPI and to complete this concept of patella height assessment.

\section{Conflict of Interest}

None. 

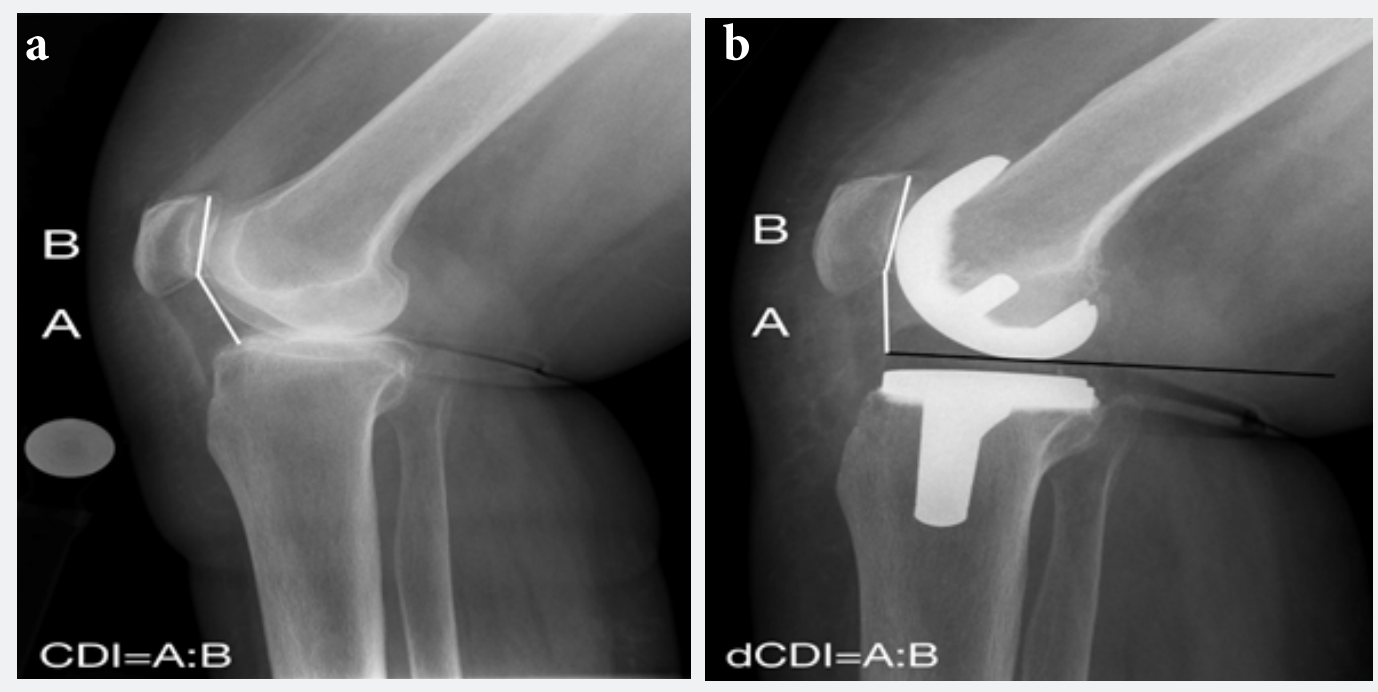

CDI: Caton-Deschamps Index; dCDI: Derived Caton-Deschamps Index

Figure 1: Caton-Deschamps Index for native knees (a) and derived Catons-Deschamps Index for arthroplasty (b).

\section{References}

1. Grelsamer RP (2002) Patella baja after total knee arthroplasty: is it really patella baja? J Arthroplasty 17(1): 66-69.

2. Aguirre-Pastor A, Ortolá DJ, Lizaur-Utrilla A, Rosa MA, Lopez-Prats FA (2020) Is pseudo-patella baja really a serious complication of total knee arthroplasty? J Arthroplasty 35(2): 557-562.

3. Bugelli G, Ascione F, Cazzella N, Franceschetti E, Franceschi F, et al. (2018) Pseudo-patella baja: a minor yet frequent complication of total knee arthroplasty. Knee Surg Sports Traumatol Arthrosc 26(6): 18311837.

4. Lum ZC, Saiz AM, Pereira GC, Meehan JP (2020) Patella baja in total knee arthroplasty. J Am Acad Orthop Surg 28(8): 316-323.

5. Insall J, Salvati E (1971) Patella position in the normal knee joint. Radiology 101(1): 101-104.
6. Verhulst F V, Van Sambeeck JDP, Olthuis GS, van der Ree J, Koëter S (2020) Patellar height measurements: Insall-Salvati ratio is most reliable method. Knee Surg Sports Traumatol Arthrosc 28(3): 869-875.

7. Caton J, Deschamps G, Chambat P, Lerat JL, Dejour H (1982) Patella infera. Apropos of 128 cases. Rev Chir Orthop Reparatrice Appar Mot 68(5): 317-325.

8. Van Duijvenbode D, Stavenuiter M, Burger B, van Dijke C, Spermon J, et al. (2016) The reliability of four widely used patellar height ratios. Int Orthop 40(3): 493-497.

9. Caton JH, Prudhon JL, Aslanian T, Verdier R (2016) Patellar height assessment in total knee arthroplasty: a new method. Int Orthop 40(12): 2527-2531.

10.Xu B, Xu W-X, Lu D, Sheng H-F, Xu X-W, et al. (2017) Application of different patella height indices in patients undergoing total knee arthroplasty. J Orthop Surg Res 12: 191.

\section{Your next submission with Juniper Publishers will reach you the below assets}

- Quality Editorial service

- Swift Peer Review

- Reprints availability

- E-prints Service

- Manuscript Podcast for convenient understanding

- Global attainment for your research

- Manuscript accessibility in different formats ( Pdf, E-pub, Full Text, Audio)

- Unceasing customer service

Track the below URL for one-step submission https://juniperpublishers.com/online-submission.php 